\title{
Alternating Gender: Individuals Who Frequently Switch Between Feeling Male and Female
}

Authors:

Laura K Case $\mathrm{PhD}^{1,2}$, Tracy Alderman $\mathrm{PhD}^{3}$, Radhika Gosavi BA ${ }^{1,4}$, V. S. Ramachandran $\mathrm{PhD}^{1}$

${ }^{1}$ Center for Brain and Cognition, 0109 Mandler Hall, University of California, San Diego, 9500 Gilman Drive, La Jolla, CA 92093

${ }^{2}$ National Center for Complementary and Integrative Health, 10 Center Drive, MSC 1302, Bethesda, MD 20892

3 Department of Psychiatry, University of California, San Diego, 9500 Gilman Drive, La Jolla, CA 92093

4 Department of Educational Psychology, University of Wisconsin-Madison, 859 Education Sciences 1025 W. Johnson Street Madison, Wisconsin, 53706-1796

Corresponding Author:

Dr. Laura K. Case

T 301-827-0003

F 301-480-3159

laura.case@nih.gov

lkcucsd@gmail.com 


\begin{abstract}
Influences of biology, culture, and individual experience on gender identity are difficult to disentangle when cultural norms dictate that gender is binary and unchanging. Collectively, transgender individuals defy cultural norms of sex and gender. Yet even many transgender individuals experience gender as relatively stable and binary. In contrast, we aim to characterize a small minority of individuals who self-report frequent, involuntary alternation in their gender identity (Alternating Gender; AG) in an attempt to glean insight into the construction of gender identity. We conducted an online survey of 73 AG individuals (44 male natal sex), with followup phone interviews and psychological assessment of 20 participants. As in many transgender individuals, alternative gender states were frequently associated with the perception of phantom body parts of the traditionally congruent sex. Participants frequently reported that gender states were accompanied by changes in thinking, emotion, and mood, as well as shifts in sexual orientation. Many individuals reported that anger was a common trigger of male state. Elevated incidence of ambidexterity was identified, as well as elevated incidence of self-reported diagnoses of Depression, Bipolar Disorder, Post Traumatic Stress Disorder, and Autism Spectrum Disorder. Our results suggest that AG may be a previously uncharacterized gender phenomenon not explained by existing psychological diagnoses or commonly recognized gender identities. Further research on AG may yield novel insight into the neural and psychological correlates of gender identity by allowing the study of gender variation within individuals over time.
\end{abstract}

Key words: Alternating gender, gender identity, transgender, Bipolar Disorder, ambidexterity 


\section{Introduction}

Sex and gender are traditionally conceived of as forming binary pairs: male sex with male gender, and female sex with female gender. Indeed, we usually regard sex as an axiomatic foundation of our biological and social existence. Yet aspects of physical sex such as chromosomes, sex hormones, anatomy, and gonads frequently do not align with categories of male or female, as evidenced by individuals with intersex conditions or so-called disorders of sexual development (e.g. (Ainsworth, 2015)). Similarly, binary categories of gender are challenged by individuals who identify as non-binary, "third gender," bigender, agender, or genderqueer: individuals whose gender is not easily categorized as male or female. Little is known about the interplay of biological and social factors in shaping gender identity.

While strength of gender identity fluctuates over time (e.g. (Burke \& Cast, 1997; Twenge, 1997)), few individuals make categorical shifts in gender and sex over their lifetime. Transsexual individuals, who shift in sex and/or gender relative to their natal sex (and traditionally congruent gender), likely comprise less than $1 \%$ of the population (e.g. (Kuyper \& Wijsen, 2014)). Individuals who identify as gender-fluid experience changes in gender identity over time (e.g. (Diamond \& Butterworth, 2008)). We recently reported on a sub-group of individuals who experience frequent, large and involuntary changes in their gender ("Alternating Gender Incongruity"; (Case \& Ramachandran, 2012)). Because not all of these individuals report experiencing their anatomy and alternating gender identity as incongruous, we now refer to this experience simply as "Alternating Gender" (AG). Individuals with AG present a 
fascinating opportunity to study variation in gender identity while physical aspects of sex are held constant.

We previously reported on $32 \mathrm{AG}$ individuals who claimed to experience regular, involuntary alternation in their gender identity between male and female (or, infrequently, other gender identities such as an agender or third gender state). The majority of these AG individuals reported sensations of phantom breasts or genitals during alternate gender states, exhibited decreased lateralization of handedness, reported increased rates of mood disorders including Bipolar Disorder (BD). In the current paper we report data from this same survey in a substantially expanded sample size (Study $1 ; N=73$; inclusive of the previous participants). In addition, we report the results of semi-structured interviews and psychological assessment of 20 of these AG individuals (Study 2). All studies were conducted in accordance with approval from the University of California, San Diego Human Research Protections Program. Informed consent was obtained online or verbally from all participants. As approved by the UC San Diego Human Research Protections Program, some participants opted to waive documented consent and instead consent verbally, so as to avoid any record linking their name to the study.

\section{Materials and Methods}

\section{Study 1 Participants:}

AG participants were recruited through an internet forum created by and for individuals who identify as bigender with a link to our online survey. We stated that we were researchers 
from the University of California, San Diego looking to learn more about individuals who experience regular switching of gender. No compensation was provided. Of 88 participants who completed the survey, 7 were excluded because they did not report alternating gender states. One participant was excluded because of a self-reported diagnosis of multiple personality/dissociative identity disorder (DID, a diagnosis that might provide an alternative explanation for their multiple gender experiences), and 7 were excluded for possible DID because they reported some amnesia for certain gender states. Data from the remaining 73 participants were included in analysis. Participants' mean age was 29.2 ( $\mathrm{SD}=11.6$, range 16-64 years). Participants were geographically broadly distributed across the United States and a small number of participants resided in other countries.

\section{Study 1 Procedure:}

The full survey and methods were previously published in (Case \& Ramachandran, 2012). The online survey included basic demographic information, the Edinburgh Handedness Inventory (Oldfield, 1971), a question about psychological diagnoses the participant had received, and questions about gender identity, gender switching, and phantom body parts. Data analysis was restricted to participants who reported experiencing alternating gender states (AG).

\section{Study 2 Participants:}

All survey participants from Study 1 who indicated interest in further research were invited to participate in Study 2, which consisted of an interview and a psychological assessment, both conducted by phone by the first author (a female graduate student in psychology). Twenty 
participants (19 from Study 1 and one who contacted us after Study 1) completed Study 2 (14 male natal sex; mean age $=36.1, \mathrm{SD}=12.3$, missing age of two participants).

\section{Study 2 Procedure:}

Psychological Assessment

Participants were assessed for DSM Axis-1 disorders using the Mini International Neuropsychiatric Interview (Sheehan et al., 1998). Participants were also assessed for levels of dissociation using the Dissociative Experiences Scale (DES; (Bernstein \& Putnam, 1986);(Carlson \& Putnam, 1993)). Bernstein \& Putnam (Bernstein \& Putnam, 1986) describe dissociation as "a lack of the normal integration of thoughts, feelings, and experiences into the stream of consciousness and memory." Dissociation is believed to be more prevalent in individuals with major mental illness and shows strong predictive validity for diagnosis of Multiple Personality Disorder (MPD/DID) and PTSD (Van IJzendoorn \& Schuengel, 1996). Assessment was conducted by the first author and supervised by the second author, a clinical psychologist, who followed up with participants when diagnoses were not clear (in two cases follow-up was not possible). One participant was excluded for a psychotic disorder and another for suspected DID. One additional participant did not complete the psychological assessment but did complete the semi-structured interview that followed.

\section{Semi-structured Interview}

In the interview portion we verbally reviewed participants' online survey responses to confirm their responses and allow for elaboration. Participants were then asked to describe their 
history of gender alternation including when they first noticed alternation, how frequently they tended to switch, and any patterns or triggers they had observed for their switches (including whether any particular emotions triggered their switches). Participants were also asked whether they observed any physiological differences between states (i.e., changes in their body or its functioning), whether crying was more frequent or easy in either state, and whether they had any experiences taking any kind of hormones. Participants with female natal sex were asked whether they experienced regular menses and whether menstruation followed or interacted with their gender state in any way. Participants with male natal sex were also asked whether they had ever felt like they had a kind of menstrual cycle after several participants spontaneously reported this. All participants were asked to describe their sexual orientation and asked to rate their relative attraction to men versus women for each gender state (where 1 = exclusive male attraction and $10=$ exclusive female attraction).

\section{Results}

Sex, gender, and gender switching

Forty-four of the 73 participants $(60 \%)$ reported male natal sex. Only 1 participant (male sex) reported undergoing chromosomal sex testing and reported a normal XY karyotype. None of the included participants reported any intersex diagnosis. Ten participants reported currently taking hormones (estrogen, Spironolactone, and/or Finasteride, a synthetic antiandrogen). Hormones were taken to alter the appearance of the body and/or in an attempt to reduce gender switching. 
The frequency of reported gender switching was highly variable, ranging from multiple times per day to several times per year. A strong majority (79\%) of participants, however, reported that their gender switched at least daily or weekly (see Figure 1). Twenty-two of 73 of the participants $(30 \%)$ reported that their gender switches were "predictable."

<Figure 1. Self-reported frequency of gender switches $(N=71)$. $>$

Self-reported psychological diagnoses $(N=73)$ :

Compared to estimates of mental illness in the adult population at large (NIMH Mental Illness Prevalence Statistics; (Hasin, Goodwin, Stinson, \& Grant, 2005)), AG participants reported elevated rates of Major Depressive Disorder (MDD), BD, Autism Spectrum Disorder (ASD), and Post Traumatic Stress Disorder (see Table 1). Many participants reported multiple diagnoses.

\section{Phantom body parts}

Forty-eight of 68 participants (71\%) reported phantom body parts (e.g. breasts or penis) and rated them as moderate in perceptual strength (2.7 on a scale of $1=$ weak and $5=$ very strong). The phantoms were perceived either "most of the time" or "at least once a day" by approximately $40 \%$ of the participants with phantoms; the other $60 \%$ reported sensing the phantom body parts “once in a while." For $62 \%$ of participants with phantom body parts, the phantom body parts "always" or "almost always" switched along with their gender state; for 29\% alignment of switching was less consistent, and for $9 \%$ alignment was rare. Twenty-one percent 
of participants with phantoms reported that the phantom body parts sometimes got "stuck" in the “wrong” gender, and an additional $28 \%$ reported this happening on rare occasion. Fifty-one percent reported that phantom body parts never occurred in the "wrong" gender. In Study 2 (below), when asked about their phantom body parts, AG participants always discussed breasts or genitals as their predominant phantom body parts; several also discussed a sense of altered body size and shape.

\section{Handedness}

Twelve of 69 AG participants (17\%) reported being ambidextrous (see Figure 2; one additional participant indicated having been ambidextrous as a child before being forced to choose a single hand to use). This rate was higher than the 2 of 62 (3.2\%) of non-AG control participants (data from an unrelated cognition study in healthy adults, matched for sex ratio) who indicated being ambidextrous (chi-square $\left.\mathrm{c}^{2}(1, N=131)=49.1, p<0.0001\right)$ and higher than population estimates of $<1 \%$ (Rodriguez et al., 2010). Thirteen of 69 (19\%) AG participants identified as left-handed, a rate not significantly different from the 9 of $62(14.5 \%)$ left-handed control subjects $\left(c^{2}(1, N=131)=0.80, p=0.37\right)$ or from population estimates of around $10 \%$ (Hardyck \& Petrinovich, 1977). On the Edinburgh Handedness Inventory AG participants received lower scores than controls, indicating a lesser degree of right-handedness $(\mathrm{AG}$ Mean $=$ $0.53, \mathrm{SD}=0.95 ;$ control $\mathrm{M}=0.91, \mathrm{SD}=0.92 ; t(128)=2.29$, two-tailed $p=0.02) . \mathrm{AG}$ participants also received scores significantly closer to zero (closer to ambidextrous; $\mathrm{M}=0.96$, $\mathrm{SD}=0.51)$ than controls $(\mathrm{M}=1.19, \mathrm{SD}=0.50 ; t(128)=2.63$, two-tailed $p=0.01)$ 
<Figure 2. Handedness of AG and non-AG Individuals>

Psychological diagnoses $(N=19)$ :

Compared to the 12-month prevalence of mental illness in adults in general (NIMH, 2015), the sub-sample of AG individuals interviewed by phone appeared to exhibit heightened rates of $\mathrm{MD}$ and $\mathrm{BD}$, as well as potentially $\mathrm{PTSD}$, compared to estimated general prevalence (NIMH, 2015) (see Table 2). The prevalence of a Bipolar Spectrum diagnosis (inclusive of past manic or hypomanic episodes) was $26 \%$, higher than the estimated national prevalence of $6.4 \%$ (Judd \& Akiskal, 2003). Agoraphobia and OCD were reported in one individual.

Dissociative Experiences Scale $(N=19)$ :

A score above 30 on the DES indicates a higher likelihood of a DID diagnosis. Mean score on the DES was $9.8(\mathrm{SD}=7.0)$ and no participant scored above 30 .

Interview $(N=20)$ :

Sexual orientation

Male natal sex $(N=14)$ : 13 of 14 male sex participants reported being predominantly attracted to women during male states. 12 of these participants became more attracted to men during their female states, including 3 whose preference switched to men during female states and one whose preference became equal. One participant reported being bisexual and said his attractions were consistent between gender states. On average male sex participants rated their 
attraction to women significantly higher during male state $(\mathrm{M}=8.7, \mathrm{SD}=1.4)$ than during female state $(\mathrm{M}=5.5,2.0 ;(t(12)=4.82, p<0.001)$.

Female natal sex $(N=6)$ : for 5 of 6 female sex participants, sexual attraction did not change across gender states. 4 of these participants reported equal attraction to men and women, and one reported consistent attraction to women. In contrast, 1 participant reported that their attraction changed with gender state but was usually homosexual with respect to that gender state. Mean ratings did not differ between male state $(\mathrm{M}=5.4, \mathrm{SD}=2.7)$ and female state $(\mathrm{M}=$ $6.8, \mathrm{SD}=2.3) ; t(5)=1.00, p=0.36)$.

\section{Menstrual cycle}

5 of 6 of the female sex individuals interviewed reported normal menstrual cycles. 1 had Polycystic Ovarian Syndrome (PCOS) and reported an absence of menstruation. 4 of the 5 menstruating female sex AG individuals reported noticing an interaction between their menstrual cycle and gender switching. 2 participants said that they always or almost always switched back to female state a few days before their period. A third reported typically experiencing a strong female state during menstruation. A fourth reported being likely to switch into a male state the day after menstruation ended. Only 1 participant was currently on birth control. Two participants reported interactions between hormonal birth control use (past or present) and gender states. For one participant, male states were more common when off of birth control. Another participant reported missing a dose of birth control and then taking a double dose and feeling "super female." 
Surprisingly, 4 male sex individuals reported experiencing some semblance of a menstrual cycle indicated by changes in mood and/or gender state about once a month. For example, one participant reported that every 3-4 weeks he had an extremely feminine gender state for 5-7 days, and then spent 3-4 days in a male state. Another participant reported a sort of phantom menses and said he felt he had missed his normal menstrual cycle the previous month.

\section{Hormones}

Three male sex participants reported unusual hormonal history. 1 reported a very delayed puberty, 1 reported stunted growth as a teenager and consequent administration of human growth hormone, and 1 reported a diagnosis of low testosterone (one of the participants who perceived a latent menstrual cycle). Three male sex participants were taking exogenous hormones or hormone-suppressing medications. One took spironolactone and estradiol and felt it had no influence on his AG except for one time when took a double dose and felt more feminine. A second participant took finasteride and spironolactone, and a third took estrogen and spironolactone. These participants generally desired a more malleable body that could more easily transition between gender presentations. None of the female sex participants were taking exogenous hormones other than birth control. The participant with PCOS had high testosterone levels.

Gender Switching Triggers and Patterns 
Female and male sex participants reported similar triggers for their switching and associations with each gender state. Frequently mentioned (by $20 \%$ or more of participants) experiences or behaviors that preceded or accompanied gender switches included the following: Heightened anger, fear, and/or threat in male state: 11 of $20(55 \%)$

Crying more easily in female state: $11(55 \%)$; more easily in male state: $1(5 \%)$

Richer emotional experience or insight in female state: 8 (40\%)

More technical/analytical interests in male state; creative interests in female state: $8(40 \%) ; 1$ reported the opposite $(5 \%)$

Voice: deeper in male state: $7(35 \%)$

Changes in touch or temperature sensitivity: 7 (35\%)

Female state associated with socializing with female friends: $5(25 \%)$

Changes in gait and/or posture: $4(20 \%)$

Changes in libido or sexual response: $4(20 \%)$

\section{Discussion}

In the current study we extend observations from (Case \& Ramachandran, 2012) suggesting a neural basis for the phenomenon of alternating gender (AG). In a survey sample of 73 individuals with AG $(60 \%$ male natal sex $)$ we found that the majority of participants reported gender switches at least once a week (the remainder experienced less frequent switches). This rate of switching is faster than that typically seen in BD (ultra-rapid and ultradian switching have been described in BD, but are uncommon (Tillman \& Geller, 2003)). Gender switching was 
commonly associated with the appearance of phantom body parts that usually switched with gender but occasionally got stuck in the "wrong" gender state. As in our previous report, we suggest that phantom breasts and genitals are not a product of the imagination, but a sensory experience akin to that seen in phantom limbs after amputation (V. S. Ramachandran \& Hirstein, 1998) and often reported by transsexual individuals (V. Ramachandran \& McGeoch, 2007). The unwelcome nature of many gender switches, and the occasional phantom persisting into the "wrong" gender state, argue against confabulation of this experience. In addition, as in our previous report, our expanded sample of AG individuals exhibited increased ambidexterity. This observation hints at a potential mechanism related to abnormal interhemispheric connectivity, discussed later in this section.

Changes in mood and cognition were also commonly reported to correlate with gender states. In our interviews with $19 \mathrm{AG}$ individuals the most frequent observation regarding emotional states as triggers was that male state was often brought about by anger, often in response to a threat. Male state frequently (but not universally) was described as a more activated, energized, or goal-oriented state. It was also associated with more technical interests. In contrast, female state was associated with greater emotional expression and emotional understanding, heightened creativity, and greater likelihood of crying or feeling overwhelmed. Gender states were accompanied by reported changes in voice, gait, and/or somatosensory sensitivity in a significant minority of individuals. In several individuals striking physiological differences were reported between gender states similar to those that have been observed in DID (e.g. (Henninger, 1992)). These findings were mirrored in the larger survey sample; numerous participants reported that gender states were accompanied by changes in thinking, emotion, and 
mood. In many AG individuals shifts in gender state were also accompanied by shifts in sexual orientation. Most male sex AG individuals reported being primarily attracted to women during male state, but becoming more attracted to men during female state. In contrast, most of the female sex participants showed a different pattern: most were attracted to both men and women, and most showed stable attraction levels across both gender states.

Our AG survey sample self-reported elevated rates of MDD, BD, PTSD, and ASD diagnoses, but no intersex conditions. Psychological screening of the sub-sample of 19 individuals confirmed elevated rates of MDD, BD, and PTSD (assessment of ASD was not conducted). It is not clear whether the heightened rates of psychiatric conditions in this sample is related to predisposition for $\mathrm{AG}$, or whether individuals with $\mathrm{AG}$ may simply have higher risk factors for psychopathology due to the stigma and stress of having an unusual and unrecognized type of gender identity. Most participants we interviewed expressed gender dysphoria during one gender state, but many also expressed valuing both gender identities and described their distress as related to public perception of their identity rather than the experience itself. Some studies find higher rates of psychological disorders including MDD in transsexual individuals; $62.7 \%$ of the participants in a study by Mazaheri et al (Mazaheri Meybodi, Hajebi, \& Ghanbari Jolfaei, 2014) had at least one psychiatric comorbidity, similar to the current AG rate of $66 \%$. However, several other studies of transsexual individuals show little to no elevation in psychopathology (e.g. (Cole, O'Boyle, Emory, \& Meyer III, 1997; Haraldsen \& Dahl, 2000)). Transsexual individuals do appear to show an elevated rate of ASD; a recent report estimated a prevalence of 5.5\% for ASD in individuals being treated for gender dysphoria (Pasterski, Gilligan, \& Curtis, 2014), very similar to our AG self-reported ASD rate of 7\%. It is also 
interesting that Generalized anxiety Disorder- another common mood disorder- did not appear to be elevated in AG, suggesting a potential link between AG and MDD and BD.

We previously speculated that the elevated prevalence of BD in AG individuals might point to abnormal hemispheric switching (e.g. stronger switching) as a mechanism underlying both conditions (for BD, see Pettigrew \& Miller (Pettigrew \& Miller, 1998)). Recent work has provided stronger evidence for white matter abnormalities in the corpus callosum and abnormal inter-hemispheric integration in BD (Leow et al., 2013). Further, Yamada et al (Yamada et al., 2015) have recently linked both BD and MDD to reduced functional anisotropy of anterior callosal fibers. Trauma has been associated with reduction of the corpus callosum and is thus a potential mechanism that could underlie abnormalities in interhemispheric switching (Brietzke et al., 2012). Trauma also underlies PTSD, which was elevated in our sample, and 30-50\% of adults with BD (also elevated in our sample) report traumatic or abusive experiences in childhood (Brietzke et al., 2012). BD may be associated with abnormalities of the left prefrontal cortex (e.g. (Blumberg et al., 2003)) and reduced left hemispheric white matter (Kieseppä et al., 2003). Further, repetitive transcranial magnetic stimulation (rTMS) has been found on occasion to switch depressed patients into mania or hypomania, using parameters associated with activation of the left frontal cortex (Krstić \& Ilić, 2013).

Our sample also showed elevated ambidexterity, a providing another potential link to abnormalities in hemispheric dominance. Ambidexterity appears to be associated with bisexuality (Blanchard \& Lippa, 2007), a sexual orientation that was elevated in our sample. Little work has been conducted on ambidexterity, but some work on non-right-handedness in general has found a higher rate of atypical language lateralization (Szaflarski et al., 2002). Non- 
right-handed individuals also show increased right hemisphere activity and elevated rates of psychopathology and withdrawal-related affect (Propper, Pierce, Geisler, Christman, \& Bellorado, 2012). In our sample, male state was commonly associated with and triggered by threat and anger. Expression of anger has been linked to frontal cortical asymmetry (Hewig, Hagemann, Seifert, Naumann, \& Bartussek, 2004), and increased anger and hostility have been associated with increased asymmetry in hemispheric activation (Propper, Brunyé, Christman, \& Bologna, 2010; Propper, Januszewski, Christman, \& Brunyé, 2011). The corpus callosum has been suggested to underlie changes in interhemispheric connectivity that appear to mediate the frontal cortical asymmetries seen in anger and aggression. Indeed, leftward dominance in the prefrontal cortex has been observed in men, in contrast to bilateral dominance in women (Chuang \& Sun, 2014). Similarly, a number of studies have shown greater lateralization in affective processing in men than in women, and some have shown greater lateralization in language and cognitive functions as well (Wager, Phan, Liberzon, \& Taylor, 2003). The association of ambidexterity with abnormal hemispheric lateralization and the associations between male gender state, anger, and left hemisphere dominance suggest that the increased rate of ambidexterity in AG individuals may also relate to abnormal hemispheric switching. Further, Savitz et al (Savitz, Solms, Pietersen, Ramesar, \& Flor-Henry, 2004) report a case of cooccurring BD and DID. The patient's switches in personality coincided with manic and hypomanic symptoms and were associated with changes in handedness, suggesting potential nosologic overlap of $\mathrm{BD}$ and mixed handedness as well as shifts in personality. Switches in gender state might share certain common mechanisms with switches in personality. 
AG does not appear to be associated with exogenous hormone administration as the majority of participants had no history of taking hormones. However, in our sample, interactions with the menstrual cycle and with birth control appear likely, with some female sex participants reporting menstruation to be preceded and accompanied by a female state and reporting associations between birth control use and more frequent or stronger female states. Some abnormal hormonal conditions were also reported in participants of each natal sex, but only in a minority of participants.

Sexual differentiation at the chromosomal/cellular level is another possible source of variation in sex and gender within an individual that might contribute to AG. Indeed, it has been argued that the brain is intersex, composed of a mosaic of independent "male" and "female" brain characteristics (Joel, 2011). Different brain regions respond differently to sex-specific signals (including hormones), and changes in gonadal hormones likely contribute to changes in sex differences over the lifespan of an organism (enhancement or suppression) (McCarthy \& Arnold, 2011). Whether such changes could occur rapidly and strongly enough to underlie AG is an open question. Furthermore, mosaicism (when cells receive different proportions of each chromosome) and microchimaerism (when a fetus exchanges stem cells with the mother through the placenta; these maternal cells can remain in offspring into adulthood) are possible sources of sex differences in different regions of the brain (Maloney et al., 1999). AG could also be linked to BD through related genetic abnormalities. Mouaffak et al (FAYCAL MOUAFFAK, THIERRY GALLARDA, NICOLAS BAUP, JEAN-PIERRE OLIÉ, \& Krebs, 2007) report a case study of a patient with gender dysphoria and BD who had mosaicism with one cell line presenting ring Y chromosome. The SRY gene involved in sexual differentiation is close to the 
telomeric region often deleted in ring $\mathrm{Y}$ that contains genes that have been linked to BD and ASD (FAYCAL MOUAFFAK et al., 2007).

Our early investigations of AG are limited by the self-report nature of the majority of our testing. However, our preliminary data suggest that AG may be a biological phenomenon and is not psychotic in origin. To our knowledge only one potential historical reference to gender alternation as pronounced as AG has been identified. In Pali Buddhist texts cases are brought before the Buddha about monks and nuns who undergo changes in features of gender and/or sex (the word used has an ambiguous meaning). These changes often occur overnight, and sometimes recur several times (Anderson, 2016). This fascinating parallel suggests that the experience of AG might extend across different cultures and time periods, suggesting a biological basis of AG. Further, it has not escaped our notice that many far-flung world cultures and civilizations have independently implied in their mythology and folklore that left is "feminine" and right "masculine" (a well-known icon of Lord Shiva in India is in his gynandromorphic form- left female, right male). This parallel independent emergence may be true for trivial reasons (e.g. the left hand is weaker and women are considered the "weaker sex" by men)- or it may be a deep reflection of brain anatomy and hemispheric specialization.

The hemispheric switching hypothesis can be further tested by reversible activation or deactivation of the left versus right hemisphere using either vestibular-caloric stimulation or transcranial magnetic stimulation (TMS), which might result in "online" gender switching. If such experiments are successful, they would have the extraordinary implication that even one's gender- which we regard as one of the pillars of our existence- far from being hard-wired in static brain anatomy- may be highly malleable and based on dynamic brain states and fluctuating 
inter-hemispheric equilibria. The switching of mental states present in AG exhibits parallels to other cyclic cognitive and affective phenomena as well. More research is needed on the multiplicity of brain states that comprise individual identities and how their shifts relate to perceptions of self, body, and gender.

Our findings, though exploratory, suggest that AG may be a novel gender-related brain phenomenon distinct from currently recognized gender identities and psychological conditions. Further research on AG may provide great insight into the biological and social factors that impact gender identity and its change over time. 
Table 1. Self-reported psychological diagnoses compared to general U.S. prevalence

\begin{tabular}{|l|c|c|c|}
\hline \multicolumn{1}{|c|}{ Diagnosis } & \multicolumn{2}{|c|}{ Sample Prevalence $(N=$} & $\begin{array}{c}\text { NIMH } \\
\text { estimated } \\
\text { Lifetime }\end{array}$ \\
& \multicolumn{2}{|c|}{ Prevalence } \\
\hline Depression & 41 & $56 \%$ & $13.2 \%^{1}$ \\
\hline Anxiety disorder (any) & 21 & $29 \%$ & $28 \%^{2}$ \\
\hline Post Traumatic Stress & 15 & $21 \%$ & $6.8 \%^{2}$ \\
\hline Disorder (PTSD) & & & \\
\hline Bipolar Disorder (BD) & 14 & $19 \%$ & $3.9 \%^{2}$ \\
\hline Autism Spectrum & 5 & $7 \%$ & $1.5 \%^{3}$ \\
Disorder (ASD) & & & \\
\hline Other & & & \\
\hline No diagnoses & 25 & $34 \%$ & \\
\hline
\end{tabular}

${ }^{1}$ Hasin et al. 2005 lifetime prevalence ((Hasin et al., 2005))

${ }^{2} \mathrm{NIMH}$ lifetime prevalence

${ }^{3} \mathrm{NIMH}$ lifetime prevalence in 8 year olds

${ }^{4} N=1$ for each of ADHD, ADD, OCD, Tourette's syndrome, Schizophrenia, and Schizoid Personality Disorder 
Table 2. Results of psychological screening compared to general U.S. Prevalence

\begin{tabular}{|c|c|c|c|}
\hline Diagnosis & \multicolumn{2}{|c|}{$\begin{array}{c}\text { Sample Prevalence }(N= \\
19)\end{array}$} & $\begin{array}{c}12 \text { Month } \\
\text { Prevalence }^{1}\end{array}$ \\
\hline Major Depression & 9 & $47 \%$ & $6.9 \%$ \\
\hline $\begin{array}{l}\text { Bipolar Disorder } \\
\text { (BD) }\end{array}$ & 3 & $16 \%$ & $2.6 \%$ \\
\hline $\begin{array}{l}\text { Post Traumatic Stress } \\
\text { Disorder (PTSD) }\end{array}$ & 2 & $11 \%$ & $3.5 \%$ \\
\hline $\begin{array}{l}\text { Generalized Anxiety } \\
\text { Disorder }\end{array}$ & 2 & $11 \%$ & $5.1 \%$ \\
\hline $\begin{array}{l}\text { Manic or Hypomanic } \\
\text { Episodes }\end{array}$ & 2 & $11 \%$ & \\
\hline Panic Disorder & 1 & $5 \%$ & $2.7 \%$ \\
\hline Agoraphobia & 1 & $5 \%$ & $0.8 \%$ \\
\hline $\begin{array}{l}\text { Obsessive } \\
\text { Compulsive Disorder } \\
\text { (OCD) }\end{array}$ & 1 & $5 \%$ & $1.0 \%$ \\
\hline
\end{tabular}




\begin{tabular}{|l|c|c|c|}
\hline $\begin{array}{l}\text { Alcohol or Substance } \\
\text { Abuse or Dependence }\end{array}$ & 1 & $5 \%$ & $6.8 \%$ (alcohol) $^{2}$ \\
\hline No diagnoses & 6 & $32 \%$ & $18.6 \%$ \\
\hline
\end{tabular}

${ }^{1}$ NIMH (NIMH, 2015)

${ }^{2} \mathrm{NIDA}(\mathrm{NIDA}, 2015)$

$N=0$ for Social Phobia, psychotic disorders, Antisocial Personality Disorder, Anorexia Nervosa, and Bulimia Nervosa 
Figure 1

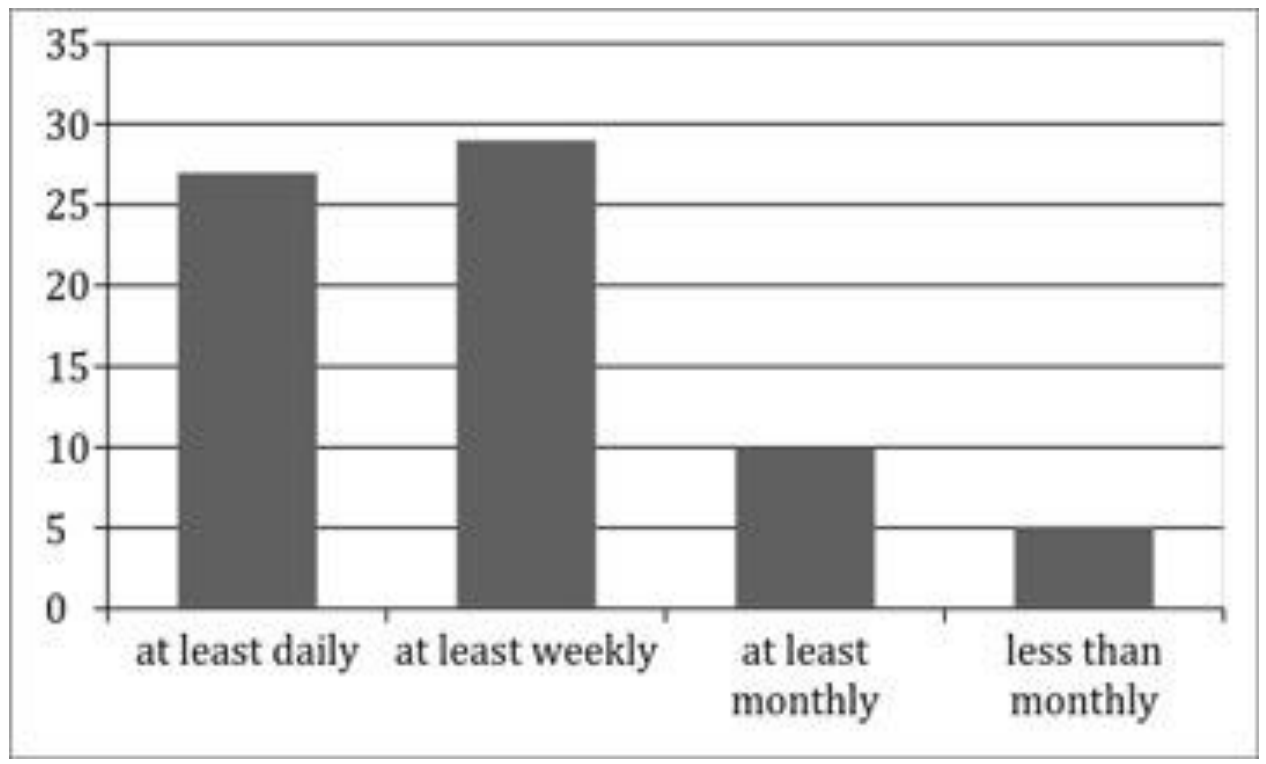

Figure 2

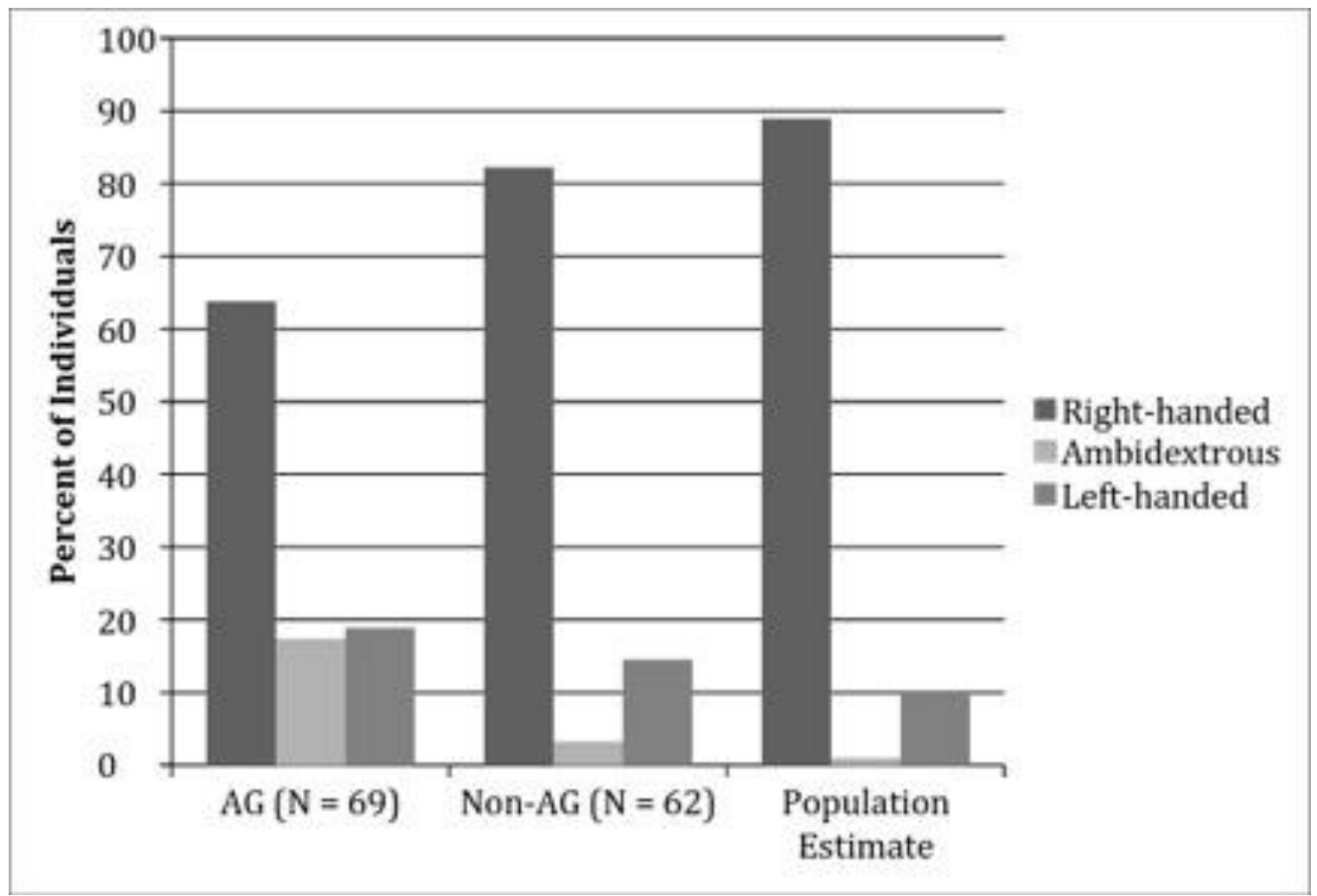




\section{Figure Legends}

Figure 1. Self-reported frequency of gender switches $(N=71)$.

AG individuals participated in an online survey advertised primarily through an online forum for bigender individuals. Participants were asked to self-report how frequently they changed gender states on average. Data from individuals who reported alternating gender without dissociation were included.

Figure 2. Handedness of AG and non-AG Individuals.

AG individuals who participated in the online were asked to self-report whether they were righthanded, left-handed, or ambidextrous. Comparison data are plotted from self-reported handedness in 62 non-AG individuals who participated in a cognitive study unrelated to gender and from a population estimate of handedness (Hardyck \& Petrinovich, 1977) are plotted for comparison. Data from the Edinburgh Handedness Inventory (Oldfield, 1971) corroborated the higher self-reported prevalence of ambidexterity among AG individuals. 


\section{Acknowledgements}

The authors thank Jeffrey Chang, David Brang, Romke Rouw, Jonathan Shan, Claire Laubacher, Brian Walitt, Catherine Bushnell, and numerous other individuals who provided assistance and feedback in this project. The first author thanks the University of California, San Diego and the National Center for Complementary and Integrative Health for support during the preparation of the manuscript. The views presented in this paper are solely those of the authors and do not necessarily reflect views of NCCIH or the NIH.

Author Contributions Statement: LC and VR designed the study. LC and RG collected and analyzed data. TA assisted with clinical assessment of participants. LC and VR wrote the paper.

Funding: This research did not receive any specific grant from funding agencies in the public, commercial, or not-for-profit sectors.

Conflicts of Interest: None 


\section{References}

Ainsworth, C. (2015). Sex redefined. Nature, 518(7539), 288-291.

Anderson, C. (2016). Changing Sex in Pāli Buddhist Texts. In B. Scherer (Ed.), Queering Paradigms (Vol. 6). Oxford: Peter Lang.

Bernstein, E. M., \& Putnam, F. W. (1986). Development, reliability, and validity of a dissociation scale. The Journal of nervous and mental disease, 174(12), 727-735.

Blanchard, R., \& Lippa, R. A. (2007). Birth order, sibling sex ratio, handedness, and sexual orientation of male and female participants in a BBC Internet research project. Archives of Sexual Behavior, 36(2), 163-176.

Blumberg, H. P., Leung, H.-C., Skudlarski, P., Lacadie, C. M., Fredericks, C. A., Harris, B. C., . . . Peterson, B. S. (2003). A functional magnetic resonance imaging study of bipolar disorder: state-and trait-related dysfunction in ventral prefrontal cortices. Archives of general psychiatry, 60(6), 601-609.

Brietzke, E., Kauer-Sant'anna, M., Jackowski, A., Grassi-Oliveira, R., Bucker, J., Zugman, A., . . . Bressan, R. A. (2012). Impact of childhood stress on psychopathology. Revista Brasileira de Psiquiatria, 34(4), 480-488.

Burke, P. J., \& Cast, A. D. (1997). Stability and change in the gender identities of newly married couples. Social Psychology Quarterly, 277-290.

Carlson, E. B., \& Putnam, F. W. (1993). An update on the dissociative experiences scale. Dissociation: progress in the dissociative disorders.

Case, L. K., \& Ramachandran, V. S. (2012). Alternating gender incongruity: a new neuropsychiatric syndrome providing insight into the dynamic plasticity of brain-sex. Med Hypotheses, 78(5), 626-631. doi:10.1016/j.mehy.2012.01.041

Chuang, C.-C., \& Sun, C.-W. (2014). Gender-related effects of prefrontal cortex connectivity: a resting-state functional optical tomography study. Biomedical optics express, 5(8), 25032516.

Cole, C. M., O'Boyle, M., Emory, L. E., \& Meyer III, W. J. (1997). Comorbidity of gender dysphoria and other major psychiatric diagnoses. Archives of Sexual Behavior, 26(1), 1326.

Diamond, L. M., \& Butterworth, M. (2008). Questioning gender and sexual identity: Dynamic links over time. Sex roles, 59(5-6), 365-376.

FAYCAL MOUAFFAK, M., THIERRY GALLARDA, M., NICOLAS BAUP, M., JEANPIERRE OLIÉ, M., \& Krebs, M.-O. (2007). Gender identity disorders and bipolar disorder associated with the ring Y chromosome. American Journal of Psychiatry.

Haraldsen, I. R., \& Dahl, A. A. (2000). Symptom profiles of gender dysphoric patients of transsexual type compared to patients with personality disorders and healthy adults. Acta psychiatrica scandinavica, 102(4), 276-281.

Hardyck, C., \& Petrinovich, L. F. (1977). Left-handedness. Psychological bulletin, 84(3), 385.

Hasin, D. S., Goodwin, R. D., Stinson, F. S., \& Grant, B. F. (2005). Epidemiology of major depressive disorder: results from the National Epidemiologic Survey on Alcoholism and Related Conditions. Archives of general psychiatry, 62(10), 1097-1106. 
Henninger, P. (1992). Conditional handedness: handedness changes in multiple personality disordered subject reflect shift in hemispheric dominance. Consciousness and Cognition, $1(3), 265-287$.

Hewig, J., Hagemann, D., Seifert, J., Naumann, E., \& Bartussek, D. (2004). On the selective relation of frontal cortical asymmetry and anger-out versus anger-control. Journal of personality and social psychology, 87(6), 926.

Joel, D. (2011). Male or female? Brains are intersex. Frontiers in integrative neuroscience, 5, 57.

Judd, L. L., \& Akiskal, H. S. (2003). The prevalence and disability of bipolar spectrum disorders in the US population: re-analysis of the ECA database taking into account subthreshold cases. Journal of affective disorders, 73(1), 123-131.

Kieseppä, T., van Erp, T. G., Haukka, J., Partonen, T., Cannon, T. D., Poutanen, V.-P., .. . Lönnqvist, J. (2003). Reduced left hemispheric white matter volume in twins with bipolar I disorder. Biol Psychiatry, 54(9), 896-905.

Krstić, J., \& Ilić, T. V. (2013). Repetitive transcranial magnetic stimulation in bipolar depression: another puzzle of manic switch. Vojnosanit Pregl, 70(6), 595.

Kuyper, L., \& Wijsen, C. (2014). Gender identities and gender dysphoria in the Netherlands. Archives of Sexual Behavior, 43(2), 377-385.

Leow, A., Ajilore, O., Zhan, L., Arienzo, D., GadElkarim, J., Zhang, A., . . Kumar, A. (2013). Impaired inter-hemispheric integration in bipolar disorder revealed with brain network analyses. Biol Psychiatry, 73(2), 183-193.

Maloney, S., Smith, A., Furst, D. E., Myerson, D., Rupert, K., Evans, P. C., \& Nelson, J. L. (1999). Microchimerism of maternal origin persists into adult life. The Journal of clinical investigation, 104(1), 41-47.

Mazaheri Meybodi, A., Hajebi, A., \& Ghanbari Jolfaei, A. (2014). Psychiatric axis I comorbidities among patients with gender dysphoria. Psychiatry journal, 2014.

McCarthy, M. M., \& Arnold, A. P. (2011). Reframing sexual differentiation of the brain. Nat Neurosci, 14(6), 677-683.

NIDA. (2015). Drug Facts. Retrieved from http://www.drugabuse.gov/publications/drugfacts/nationwide-trends

NIMH. (2015). Health and Education: Statistics.

Oldfield, R. C. (1971). The assessment and analysis of handedness: the Edinburgh inventory. Neuropsychologia, 9(1), 97-113.

Pasterski, V., Gilligan, L., \& Curtis, R. (2014). Traits of autism spectrum disorders in adults with gender dysphoria. Archives of Sexual Behavior, 43(2), 387-393.

Pettigrew, J. D., \& Miller, S. M. (1998). A 'sticky'interhemispheric switch in bipolar disorder? Proceedings of the Royal Society of London B: Biological Sciences, 265(1411), 21412148.

Propper, R. E., Brunyé, T. T., Christman, S. D., \& Bologna, J. (2010). Negative emotional valence is associated with non-right-handedness and increased imbalance of hemispheric activation as measured by tympanic membrane temperature. The Journal of nervous and mental disease, 198(9), 691-694.

Propper, R. E., Januszewski, A., Christman, S. D., \& Brunyé, T. T. (2011). Increased anger is associated with increased hemispheric asymmetry: support for anger-tympanic membrane relationships. The Journal of nervous and mental disease, 199(9), 716-720. 
Propper, R. E., Pierce, J., Geisler, M. W., Christman, S. D., \& Bellorado, N. (2012). Asymmetry in resting alpha activity: Effects of handedness.

Ramachandran, V., \& McGeoch, P. D. (2007). Occurrence of phantom genitalia after gender reassignment surgery. Med Hypotheses, 69(5), 1001-1003.

Ramachandran, V. S., \& Hirstein, W. (1998). The perception of phantom limbs. The DO Hebb lecture. Brain, 121(9), 1603-1630.

Rodriguez, A., Kaakinen, M., Moilanen, I., Taanila, A., McGough, J. J., Loo, S., \& Järvelin, M.R. (2010). Mixed-handedness is linked to mental health problems in children and adolescents. Pediatrics, 125(2), e340-e348.

Savitz, J., Solms, M., Pietersen, E., Ramesar, R., \& Flor-Henry, P. (2004). Dissociative identity disorder associated with mania and change in handedness. Cognitive and behavioral neurology, 17(4), 233-237.

Sheehan, D. V., Lecrubier, Y., Sheehan, K. H., Amorim, P., Janavs, J., Weiller, E., . . Dunbar, G. C. (1998). The Mini-International Neuropsychiatric Interview (M.I.N.I.): the development and validation of a structured diagnostic psychiatric interview for DSM-IV and ICD-10. J Clin Psychiatry, 59 Suppl 20, 22-33;quiz 34-57.

Szaflarski, J. P., Binder, J. R., Possing, E. T., McKiernan, K. A., Ward, B. D., \& Hammeke, T. A. (2002). Language lateralization in left-handed and ambidextrous people fMRI data. Neurology, 59(2), 238-244.

Tillman, R., \& Geller, B. (2003). Definitions of rapid, ultrarapid, and ultradian cycling and of episode duration in pediatric and adult bipolar disorders: a proposal to distinguish episodes from cycles. Journal of child and adolescent psychopharmacology, 13(3), $267-$ 271.

Twenge, J. M. (1997). Changes in masculine and feminine traits over time: A meta-analysis. Sex roles, 36(5-6), 305-325.

Van IJzendoorn, M. H., \& Schuengel, C. (1996). The measurement of dissociation in normal and clinical populations: Meta-analytic validation of the Dissociative Experiences Scale (DES). Clinical Psychology Review, 16(5), 365-382.

Wager, T. D., Phan, K. L., Liberzon, I., \& Taylor, S. F. (2003). Valence, gender, and lateralization of functional brain anatomy in emotion: a meta-analysis of findings from neuroimaging. Neuroimage, 19(3), 513-531.

Yamada, S., Takahashi, S., Ukai, S., Tsuji, T., Iwatani, J., Tsuda, K., . . Terada, M. (2015). Microstructural abnormalities in anterior callosal fibers and their relationship with cognitive function in major depressive disorder and bipolar disorder: A tract-specific analysis study. Journal of affective disorders, 174, 542-548. 